\section{$\underset{\substack{\text { hommes } \\ \text { \& migrations }}}{ }$}

\section{Hommes \& migrations}

Revue française de référence sur les dynamiques

migratoires

$1283 \mid 2010$

Cuisines et dépendances

\title{
Rencontres gourmandes. La cuisine de la caravane Babel
}

Caucase

Édité par Marcho Doryila, 64 pages, 25 euros

\section{Mauricette Bastide}

\section{OpenEdition}

1 Journals

\section{Édition électronique}

URL : http://journals.openedition.org/hommesmigrations/1027

DOI : 10.4000/hommesmigrations. 1027

ISSN : 2262-3353

Éditeur

Musée national de l'histoire de l'immigration

Édition imprimée

Date de publication : 1 janvier 2010

Pagination : 202-203

ISBN : 978-2-919040-04-9

ISSN : 1142-852X

Référence électronique

Mauricette Bastide, "Rencontres gourmandes. La cuisine de la caravane Babel Caucase », Hommes \& migrations [En ligne], 1283 | 2010, mis en ligne le 29 mai 2013, consulté le 22 septembre 2020. URL http://journals.openedition.org/hommesmigrations/1027 ; DOl : https://doi.org/10.4000/ hommesmigrations.1027

Ce document a été généré automatiquement le 22 septembre 2020.

Tous droits réservés 


\title{
Rencontres gourmandes. La cuisine de la caravane Babel Caucase
}

Édité par Marcho Doryila, 64 pages, 25 euros

\author{
Mauricette Bastide
}

\section{RÉFÉRENCE}

Rencontres gourmandes. La cuisine de la caravane Babel Caucase, édité par Marcho Doryila, 64 pages, 25 euros

1 Tous ceux qui ont suivi de près ou de loin le périple de la caravane Babel Caucase au printemps 2007 savent que l'aventure n'a pas vraiment pris fin au soir du 31 mai, avec son retour en France. En plus d'un site Internet ${ }^{1}$ et d'un DVD ${ }^{2}$ début 2008 , les splendides carnets de voyage de Jérôme Guerry ${ }^{3}$, publiés quelques mois plus tard, avaient déjà fait connaître la remorque manège, la roulotte scène, le camion vidéo, le bus cinéma et... la cuisine roulante. C'est maintenant un petit cahier à spirale de soixante-quatre pages épaisses qui prolonge l'aventure, en couleur et en quatre langues - français, russe, géorgien et tchétchène - presque cinq avec les nombreux termes bretons.

2 "Nous désirions les accueillir, ils voulurent nous nourrir. Nous combler. À chaque rencontre organisée pour sensibiliser et informer, les femmes tchétchènes ont tenu à nous régaler", raconte Mylène, en préface. La raison d'être du recueil de recettes se précise : festins partagés, surenchère de bonne chère, potlatch de saveurs.

3 "Nous voulions ce livre de cuisine, car les gestes du quotidien sont universels. En toutes circonstances, les femmes nourrissent le monde", rappelle Annaïg de Douarnenez. Ainsi, ce joli cahier à trente auteurs témoigne pour tous ceux et celles qui n'ont pu être du voyage, mais sans qui celui-ci n'aurait pas été aussi chaleureux, solidaire, intense...

4 "Convivial", c'est le mot que l'on hésite à utiliser tant il est galvaudé, mais qui retrouve ici sa plénitude. Un projet, en tout cas, qu'aucun dilemme agaçant ne pouvait ternir : 
afin de régaler des convives musulmans, la recette du kig ha farz, sorte de pot-au-feu breton, ne contient pas plus de porc que son cousin tchétchène, le jik jik gulnish.

De même, les pourtant fameuses caillettes de Crest ne figurent pas dans les recettes de la Drôme. Mais, à côté du délicieux tian de Maya, on trouvera des filets de harengs qui seraient bien peu drômois s'ils ne marinaient... dans l'huile d'olive. Façon de marquer discrètement l'antique diversité hexagonale, à la fois linguistique et diététique : d'oc et/ou d'oïl.

6 Mais, si les herbes de Provence dialoguent souvent avec celles des hauteurs du Caucase, "ce que Bretons et Tchétchènes ont en commun, c'est le beurre!" Sans oublier toutes les pâtes, crêpes, chaussons, beignets ou raviolis, dont on trouvera ici une bonne dizaine de variantes et déclinaisons, salées ou sucrées.

7 Au total, dix entrées, sept plats et sept desserts sont détaillés pour huit, douze, quatre ou... trente personnes. De vraies recettes pratiques, faciles à réaliser, sans faire appel à une habileté particulière ni même à des ingrédients recherchés ou des installations sophistiquées. Car ce qui déborde à chaque page de ce livre, à chaque phrase, à chaque image, c'est évidemment le plaisir de faire la fête en se régalant, mais aussi et surtout le bonheur de cuisiner ensemble.

\section{NOTES}

1. www.babelcaucase.com

2. Babel Caucase Toujours!, par Mylène Sauloy, DVD de $90 \mathrm{~min}, 20$ euros, édité par Marcho Doryila.Après avoir obtenu, dès sa sortie, le Grand Prix du documentaire au Festival international des films de femmes à Créteil, en 2008, ce film a participé à de nombreux festivals : Douarnenez, Clermont-Ferrand, Étonnants voyageurs à Saint-Malo...

3. Babel Caucase : tranches de caravane croquées, par Jérôme Guerry, 128 pages, 30 euros,édité par Marcho Doryila. 